\title{
Gender differences in episodic memory
}

\author{
AGNETA HERLITZ \\ Karolinska Institutet, Stockholm, Sweden \\ Stockholm Gerontology Research Center, Stockholm, Sweden \\ and University of Stockholm, Stockholm, Sweden \\ LARS-GÖRAN NILSSON \\ University of Stockholm, Stockholm, Sweden \\ and \\ LARS BÄCKMAN \\ Karolinska Institutet, Stockholm, Sweden \\ Stockholm Gerontology Research Center, Stockholm, Sweden \\ and Göteborg University, Göteborg, Sweden
}

\begin{abstract}
The relationship between gender and memory has been largely neglected by research, despite occasional studies reporting gender differences in episodic memory performance. The present study examined potential gender differences in episodic memory, semantic memory, primary memory, and priming. Five hundred thirty women and 470 men, randomly sampled from the city of Umeå, Sweden, 35-80 years of age, participated in the study. There were no differences between men and women with regard to age or education, or on a measure of global intellectual functioning. As has been demonstrated previously, men outperformed women on a visuospatial task and women outperformed men on tests of verbal fluency. In addition, the results demonstrated that women consistently performed at a higher level than did men on the episodic memory tasks, although there were no differences between men and women on the tasks assessing semantic memory, primary memory, or priming. The women's higher level of performance on the episodic memory tasks could not be fully explained by their higher verbal ability.
\end{abstract}

In 1974, Maccoby and Jacklin published their highly cited work on gender differences in various human abilities and functions. They concluded that girls have greater verbal ability than boys do; that boys excel in visuospatial and mathematical ability; and that males are more aggressive than females. However, Maccoby and Jacklin rejected the hypothesis of gender differences in learning and memory. Since then, virtually no systematic research has been conducted on potential gender differences in memory.

In the area of learning and memory, Maccoby and Jacklin (1974) categorized the studies that they reviewed in terms of conditioning, discrimination learning, pairedassociate learning, oddity problems, probability learning, learning through modeling, incidental learning, and memory. In retrospect, however, if one applies the current, widely used model of five separate but interacting

This research was supported by grants from the Bank of Sweden Tercentenary Foundation, the Swedish Council for Planning and $\mathrm{CO}$ ordination of Research, the Swedish Council for Research in the Humanities and Social Sciences, the Swedish Council for Social Research, and the Swedish Medical Research Council. We thank all members of the Betula project for collaboration and data collection. Correspondence should be addressed to A. Herlitz, Department of Psychology, University of Stockholm, S-10691 Stockholm. Sweden (e-mail: ahz@psychology.su.se). systems (episodic memory, primary memory, semantic memory, priming, and procedural memory; see Schacter \& Tulving, 1994, and Tulving, 1983, 1993), a pattern of gender differences does appear in the research reviewed by Maccoby and Jacklin. Specifically, when one examines the studies on episodic memory (i.e., autobiographical records of unique events in the individual's experience encoded in a particular temporal-spatial context), it is clear that there were significant differences favoring females in 17 out of the 64 reviewed experiments, whereas only 2 experiments revealed an advantage for males. Tendencies in either direction were not reported.

As noted, gender differences in memory performance have seldom been examined explicitly, although gender differences in episodic memory have occasionally been reported. Typically, such gender differences in episodic memory have been found as a by-product of some other research question and have thus not been discussed further. Recent studies reporting gender differences in episodic memory are listed in Table 1 . The majority of these studies come from research on adult age differences in memory (Hill et al., 1995; Hultsch, Masson, \& Small, 1991; Larrabee \& Crook, 1993; Rabbitt, Donlan, Watson, McInnes, \& Bent, 1995; Schaie \& Willis, 1993; West, Crook, \& Barron, 1992; Zelinski, Gilewski, \& Schaie, 1993), but gender differences have also been reported in studies done to evaluate or establish norms for memory tests 
Table 1 Previous Studies Reporting Gender Differences Favoring Women in Episodic Memory Tasks

\begin{tabular}{|c|c|c|c|c|}
\hline \multirow[b]{2}{*}{ Task } & \multirow[b]{2}{*}{ Source } & \multicolumn{2}{|c|}{$n$} & \multirow{2}{*}{$\begin{array}{l}\text { Age } \\
\text { range }\end{array}$} \\
\hline & & Women & Men & \\
\hline \multicolumn{5}{|l|}{ Word Recall } \\
\hline Rey Auditory Verbal Learning Test & Bolla-Wilson \& Bleecker (1986) & 59 & 55 & $40-84$ \\
\hline Rey Auditory Verbal Learning Test & Geffen, Moar, O'Hanlon, Clark, \& Geffen (1990) & 78 & 75 & $16-86$ \\
\hline Recall of random and categorized word lists & Hill et al. (1995) & 63 & 21 & $76-87$ \\
\hline Recall of categorized word lists & Hultsch, Masson, \& Small (1991) & 319 & 225 & $19-86$ \\
\hline Cumulative learning and recall of word lists & Rabbitt, Donlan, Watson, McInnes, \& Bent (1995) & 1,426 & 583 & $50-93$ \\
\hline Selective reminding of word lists & Ruff, Light, \& Quayhagen (1988) & 202 & 190 & $16-70$ \\
\hline Immediate and delayed recall of word lists & Schaie \& Willis (1993) & 885 & 743 & $29-88$ \\
\hline Selective reminding of grocery lists & West, Crook, \& Barron (1992) & 1,343 & 1,000 & $17-92$ \\
\hline Immediate and delayed recall of word lists & Zelinski, Gilewski, \& Schaie (1993) & 258 & 250 & $55-84$ \\
\hline \multicolumn{5}{|l|}{ Word Recognition } \\
\hline Warrington's recognition test for words & Temple \& Cornish (1993) & 64 & 64 & $9-11$ \\
\hline Recognition of word lists & Zelinski et al. (1993) & 258 & 250 & $55-84$ \\
\hline \multicolumn{5}{|l|}{ Story Recall } \\
\hline Recall of narrative stories & Hultsch et al. (1991) & 319 & 225 & $19-86$ \\
\hline Recall of short essay & Zelinski et al. (1993) & 258 & 250 & $55-84$ \\
\hline \multicolumn{5}{|l|}{ Face and Name Recall and Recognition } \\
\hline Recognition of faces of unfamiliar persons & Hill et al. (1995) & 63 & 21 & $76-87$ \\
\hline Cued recall of names by faces & Larrabee \& Crook (1993) & 417 & 417 & $17-79$ \\
\hline Recognition of women's and children's faces & McKelvie, Standing, St. Jean, \& Law (1993) & 10 & 10 & ${ }^{*}$ \\
\hline Recognition of faces of familiar persons & Wahlin et al. (1993) & 181 & 47 & $75-96$ \\
\hline Cued recall of names by faces & West et al. (1992) & 1,343 & 1,000 & $17-92$ \\
\hline \multicolumn{5}{|l|}{ Spatial Recall } \\
\hline Recall of objects on paper and real-life locations & Eals \& Silverman (1994) & 40 & 40 & * \\
\hline Recall of objects in real-life locations & Hill et al. (1995) & 63 & 21 & $76-87$ \\
\hline \multicolumn{5}{|l|}{ Picture Recall } \\
\hline Landmarks on a map & Galea \& Kimura (1993) & 48 & 49 & $18-29$ \\
\hline \multicolumn{5}{|l|}{ Odor Recognition } \\
\hline
\end{tabular}

*Undergraduate students (no specific age range reported).

(Bolla-Wilson \& Bleecker, 1986; Geffen, Moar, O’Hanlon, Clark, \& Geffen, 1990; Ruff, Light, \& Quayhagen, 1988; Temple \& Cornish, 1993). Although most episodic memory research has involved verbal materials, gender differences in episodic memory have also been found with the use of other types of materials, such as faces (Hill et al., 1995; McKelvie, Standing, St. Jean, \& Law, 1993; Wahlin et al., 1993), pictures (Galea \& Kimura, 1993), locations (Eals \& Silverman, 1994; Hill et al., 1995), and odors (Lehrner, 1993). Taken together, these studies suggest that there may be gender differences in episodic memory that favor women.

Still, gender differences in episodic memory have not been reported in the majority of experimental studies on memory. This could be due to a lack of effect, but it could also be the result of a failure to assess gender differences statistically. In addition, some studies have yielded conflicting results. For example, McKelvie et al. (1993) reported gender differences in recognition memory for faces and cars. Men performed at a higher level on recognition of male faces, and they recognized more cars than did women, whereas women recognized more female faces and children than did men. The authors suggested that the obtained gender differences might reflect male and female interests and differential familiarity with different kinds of materials. Further, Temple and Cornish
(1993) reported no gender differences in face recognition among boys and girls, although there was a female advantage on recognition memory for words. Finally, Hart and O'Shanick (1993) found gender differences favoring females for verbal material, in the absence of differences for pictorial and figural stimuli.

Thus, several issues related to a potential female advantage in episodic memory remain to be addressed. First, additional evidence regarding gender differences in episodic memory is needed. Second, given that there are gender differences in episodic memory, it is important to determine whether such differences are related to the type of material employed. It is possible that women's higher performance in episodic memory tasks may reflect a higher verbal ability (Halpern, 1992; Hyde \& Linn, 1988), for most reports of gender differences in episodic memory have come from the use of verbal tasks. Third, in the vast majority of the studies reviewed above, episodic memory has been examined exclusively, while other forms of memory (e.g., primary memory, semantic memory, priming) have been ignored. Information regarding whether the superior performance of females is specific to episodic memory, or whether gender differences occur across a variety of different forms of memory, is required. Finally, it is of interest to document whether gender differences in memory are of equal magnitude across the 
Education

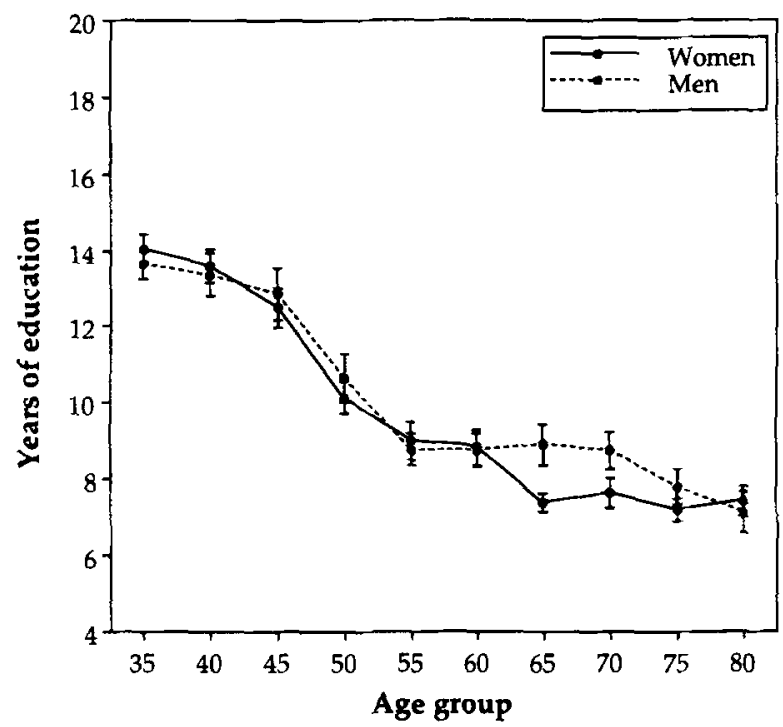

Mini-Mental State Examination

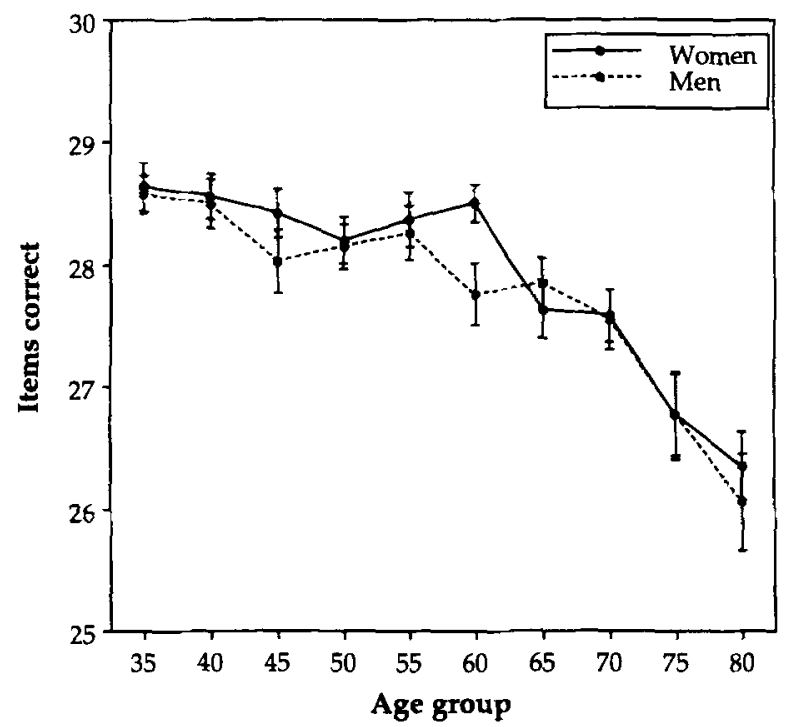

Figure 1. Means and standard errors for years of education and Mini-Mental State Examination (Folstein et al., 1975) across age.

adult life span, or whether the size of the difference varies across age. The latter is possible, given that research by Gur et al. (1991) has indicated that men show greater decline in brain volume than women do in old age.

The purpose of the present research was to extend existing knowledge concerning these issues. Specifically, using a population-based sample of 1,000 adults between 35 and 80 years of age, we addressed the following main issues: (1) Are there gender differences in memory performance, and, if so, are these differences (2) generalizable across different forms of memory, (3) a function of women's greater verbal skills, and (4) invariant across the adult life span?

\section{METHOD}

The study is a part of the Betula prospective study of memory, health, and aging. This is a Jarge-scale study, investigating how memory and health develop across the adult life span (for a detailed description of the purposes and the design of the study, see Nilsson et al., 1997).

\section{Subjects}

One thousand healthy adults ( 470 men, 530 women) participated in the study. They comprised 100 subjects in each of the following groups: 35 -year-olds ( 50 men, 50 women), 40-year-olds (48 men, 52 women), 45-year-olds ( 46 men, 54 women), 50 -yearolds ( 40 men, 60 women), 55 -year-olds ( 46 men, 54 women), 60 year-olds ( 54 men, 46 women), 65 -year-olds ( 46 men, 54 women), 70 -year-olds ( 52 men, 48 women), 75 -year-olds ( 47 men, 53 women), and 80 -year-olds (4l men, 59 women).

The subjects were randomly sampled from the population of Umeå, Sweden. In order to obtain a total of 100 subjects in each of the 10 different cohorts, a letter was sent to 1,976 persons. Of these individuals, 259 could not be located; 130 were too ill to participate; 31 had died; 481 did not want to participate or claimed that they were too busy to participate; and 89 were excluded because of a visual or auditory handicap, mental retardation, or dementia, or because they spoke a native language other than Swedish.
Finally, 17 subjects were replaced because they did not show up at the memory examination. In order to evaluate whether the 481 nonsubjects who refused to participate were similar to the 1,000 subjects, public information from the census bureau (Statistiska Centralbyrån, 1985) was gathered regarding their gender, marital status, employment, education, income, number of persons living in household, profession, category of profession, number of children living at home, type of housing, and overcrowding in household. Comparisons revealed that the subjects wete to a greater extent employed and had higher incomes than did the nonsubjects $(p<.05)$. There were no other reliable group differences, as determined by $\chi^{2}$ tests $(p>.05$; see Nilsson et al., 1997).

All subjects ( 1 ) underwent an extensive health examination, including blood sample testing; (2) participated in an interview about health status and received a revised version of the Katz activities of daily living (ADL) instrument (Hulter-Åsberg, 1984); (3) completed a questionnaire about social and economical issues; (4) completed a questionnaire about critical life events (Perris, $1984 a, 1984 b, 1984 c)$; and (5) underwent an extensive examination of memory functions. Data from subjective reports of health (i.e., subjects were asked whether they felt healthy or not, with a yes/no answer being required) revealed that an equal number of men and women perceived themselves as healthy $\left(M_{F}=76.1 \%\right.$; $\left.M_{\mathrm{M}}=73.5 \%\right)$, as determined by a $\chi^{2}$ test ( $p>.05$; see Nilsson et al., 1997)

Figure 1 shows educational background and performance on the Mini-Mental State Examination (MMSE; Folstein, Folstein, $\&$ McHugh, 1975) across the 10 age groups, and Figure 2 shows performance on tests of verbal fluency and Block Design across age. The MMSE is a widely used test for determining global cognitive status. In Fluency 1 , subjects were asked to generate as many words as possible beginning with the letter $A$ in $1 \mathrm{~min}$, and Fluency 2 involved generating as many five-letter words beginning with the letter $M$ as possible in $1 \mathrm{~min}$. Block Design is a standardized test of visuospatial ability from the Wechsler Adult Intelligence Scale-Revised (Wechsler, 1981).

Because the following analyses were based on a large sample. the alpha level for reporting statistical significance was set at .01 , unless otherwise noted. There were no age differences in gender distribution, as determined by a $\chi^{2}$ test $(p>.05)$. A multivariate analysis of variance was conducted on the education, MMSE, Flu- 
Fluency 1 and Fluency 2

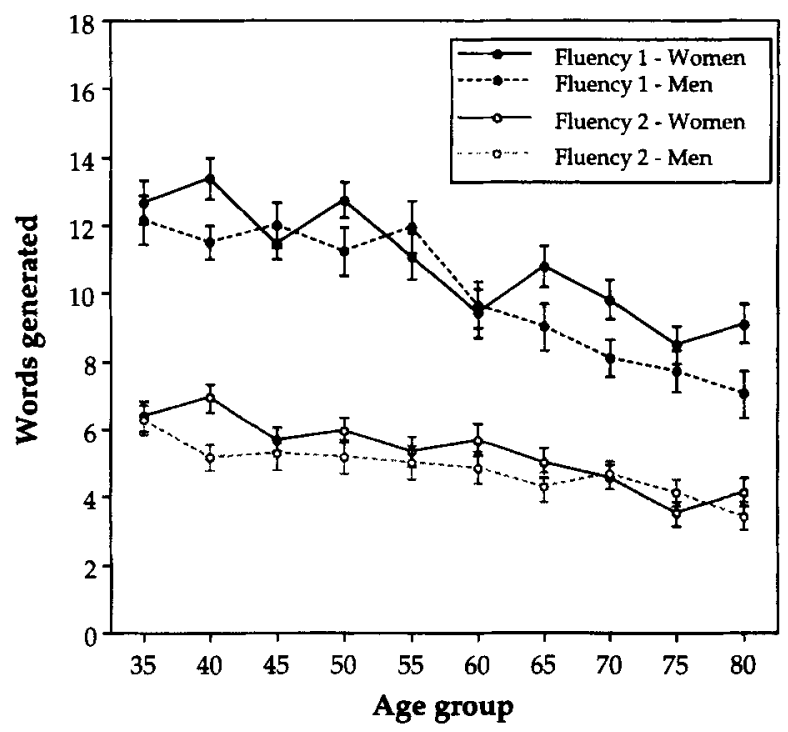

Block Design

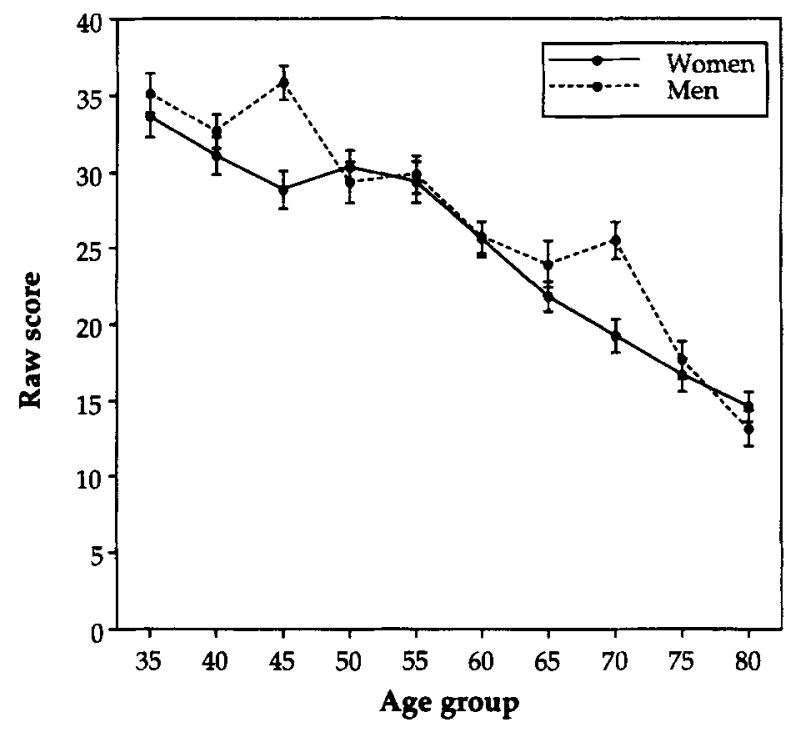

Figure 2. Means and standard errors for Fluency 1, Fluency 2, and Block Design (Wechsler, 1981) across age.

ency 1 , Fluency 2 , and Block Design data, with age and gender as independent variables. The analysis indicated significant effects of age [Wilks's $\lambda=.471, F(45,4369)=17.78$ ] and gender (Wilks's $\lambda=.964, F(5,976)=7.23]$. The age $\times$ gender interaction was not significant. In order to evaluate the effects of age and gender on education, MMSE, Fluency 1, Fluency 2, and Block Design, the information from the univariate $F$ tests in the multivariate analysis of variance (MANOVA) was examined. For education, there was a main effect of age $[F(9,980)=59.46]$, indicating that educational level decreased with advancing age. Similarly, the MMSE data revealed a significant main effect of age $[F(9,980)=$ 20.35 ], with performance decreasing across age groups. There were no gender effects for education or the MMSE. The results on Fluency 1 yielded a main effect of age $[F(9,980)=13.79]$ and a marginally significant effect of gender $[F(1,980)=5.24, p<.02]$, indicating that performance decreased with increasing age and that women performed at a higher level than did men. The Fluency 2 data also yielded main effects of age $[F(9,980)=8.06]$ and gender $[F(1,980)=6.77]$, again indicating that performance deteriorated with age and that women performed better than men. Finally, the results on the Block Design data showed main effects of age $[F(9,980)=63.61]$ and gender $[F(1,980)=10.75]$ and a significant age $\times$ gender interaction $[F(9,980)=2.70]$. These findings indicated that performance decreased with advancing age and that men performed at a higher level than did women. The interaction was due to the gender differences' being especially pronounced for the 45- and 75-year-olds. In general, these data are consistent with previous research, indicating a female advantage in verbal ability as indexed by the two fluency tests and a male superiority in visuospatial skill as indexed by the Block Design test.

\section{Materials and Procedure}

The memory tasks were selected to assess multiple domains of performance, including episodic memory, primary memory, semantic memory, and priming, although the selection of tasks was biased toward episodic memory. The memory testing was conducted by trained psychometricians and lasted between 1.5 and $2 \mathrm{~h}$ for each subject. For a detailed description of the tasks used and the structure of the test session, see Nilsson et al. (1997).

\section{Episodic Memory Tasks}

Word recall. In order to study word recall under conditions of focused and divided attention, we used a task developed by Baddeley, Lewis, Eldridge, and Thomson (1984). This task involved four different conditions. In each of these conditions, subjects were presented auditorily with a list of 12 common unrelated nouns, along with the instruction to learn these words for an immediate free recall test. The words were presented at $2-\mathrm{sec}$ intervals. The concurrent task was to sort a deck of playing cards into two piles, one red pile and one black. The card-sorting task was conducted during both study and test, during study only, or during test only. In the fourth condition, no card sorting was performed at either study or test. There were two different sets of words for each of the four conditions, which were counterbalanced across subjects in each cohort. The measure used was the number of words correctly recalled.

Memory of activities. At the end of the testing session, the subjects were incidentally asked to recall the tasks that they had performed during the testing session (Kausler \& Hakami, 1983). The number of activities correctly recalled was used as dependent measure. A maximum of 31 activities could be recalled. There was no time limit for this task.

Recall of newly acquired facts. Using parts of a paradigm developed by Schacter, Harbluk, and MacLachlan (1984), subjects were presented with 20 fictitious statements regarding famous people (e.g., "Astrid Lindgren collects stamps as a hobby"). At test, the subjects were asked questions regarding the statements (e.g., "What is Astrid Lindgren's hobby?"). The number of correctly recalled answers was the dependent measure. This task was also self-paced.

Free recall, cued recall, and recognition of sentences and subject-performed tasks. For subject-performed tasks (SPTs; Cohen, 1981), each subject was provided with 16 objects, 1 at a time (e.g., bear, book). Simultaneously with the presentation of each object, an instruction, consisting of a verb and a noun (e.g., turn over the bear, lift the book) was presented visually on an index card and read aloud by the experimenter. The subject was asked to perform each SPT during an 8-sec interval. Following presentation of the last item, subjects were given 2 min to recall as many of these SPTs as possible. The sentence task was per- 
formed in the exact same way, with the exception that no objects were presented and there were no requirements of motor action.

The nouns belonged to four different categories (e.g., animals, reading materials, kitchen utensils, articles of clothing), with four different exemplars in each category (e.g., horse, bear, alligator, squirrel). Half the subjects in each cohort were given the sentence list followed by the SPT list. A reversed presentation order of the lists was used for the other half of the subjects in each cohort. Two different sets of sentences composed the lists, with eight different orders of sentences for each set. These 16 different lists were counterbalanced across subjects in each cohort.

Immediately after free recall of the second list, a cued recall test of the nouns presented in each of these two lists was conducted. Eight category names, four from each list, were presented, and subjects were asked to recall as many target items as possible from each category. Three minutes were allotted for this cued recall task. The number of nouns recalled in free and cued recall, respectively, were used as dependent measures. In the recognition test, 16 nouns from the study lists ( 8 of which had appeared in the sentence condition and 8 of which had appeared in the SPT condition) and 16 distractor nouns from the same categories as those for the target nouns were presented in randomized order after instructions about yes/no recognition. The recognition data were transformed into $d^{\prime}$ scores.

Face-name recognition. Subjects were presented with 16 color pictures of faces of 10-year-old children, one at a time. Concurrently, a fictitious full name was presented. The name information consisted of a common Swedish given name and a common Swedish family name (Olofsson \& Bäckman, 1996). Each facename picture was in view for $8 \mathrm{sec}$. Two equivalent sets of pictures and names were used, and these were counterbalanced across age groups. The subjects were instructed to remember the faces and the last names for a later recognition test. After a 45-min interval, the subjects were presented with the 12 target faces and with 12 distractor faces not previously shown. The target and distractor faces appeared, one by one, in random order for a maximum of $15 \mathrm{sec}$ per face, and subjects were instructed to make a yes/no recognition judgment. Moreover, for faces presented at the study trial, the subjects were asked to recognize the full name presented at study in a four-alternative multiple-choice test. For face recognition, $d^{\prime}$ served as the dependent measure: for recognition of given names and family names, the number of correct recognitions was the dependent measure.

\section{Semantic Memory Tasks}

Recall of general knowledge. In addition to the questions asked to test recall of newly acquired facts, another 20 questions were presented at test. For these questions, the information was generally known (e.g., "What was the profession of Olof Palme?"; Schacter et al., 1984). The number of correctly recalled facts was used as the dependent measure. This task was self-paced.

Word comprehension. Subjects were presented with a list of 30 target words, with five alternates per target word. Among the five alternates there was one synonym for each target word, and the subjects were asked to mark the synonym for each target (Dureman, 1960). Seven minutes were allowed for this task, and the number of correctly marked synonyms was the dependent measure.

\section{Primary Memory Task}

The primary memory measure was computed from the nondivided/nondivided condition in the word recall task. Performance in this recall task was separated into its primary and secondary memory components, using the lag method devised by Tulving and Colotla (1970). In this method, words recalled within a presentation or retrieval lag of seven words are considered to be retrieved from primary memory, whereas words recalled after a longer lag are considered to be retrieved from secondary memory.
The number of correctly recalled words from primary memory was the dependent measure.

\section{Priming Task}

Subjects were presented with the first two letters of family names and were asked to say the first family name that came to mind. A total of 32 name stems were presented; 16 of these were stems for names presented in the previously described face-name recognition task, and 16 were stems of names that had not been presented to the subject before. One set of stems served as targets for one half of the subjects in each cohort, and the other set served as distractors. For the other half of the subjects in each cohort, the target and distractor sets were reversed. The purpose of including distractor stems was to obtain a baseline measure of completing name stems. The difference in completion rate between target names and distractor names resulted in the measure of priming.

\section{RESULTS}

We will start with a presentation of the results from the episodic memory tasks and then describe the data from the semantic memory, primary memory, and priming tasks. In these analyses, the direct effects of gender on performance were assessed. The potential influence of gender was also evaluated, controlling statistically for gender differences in verbal fluency. Table 2 gives an overview of the means and standard deviations for men and women in all memory tasks, as well as the effect size, $d$ (Rosenthal, 1991), for gender in each of the memory tasks. Whenever a task involved different presentation orders or versions, the effects of these variables were evaluated initially. However, there were no effects involving order or version, and the data were collapsed across these variables.

\section{Episodic Memory Tests}

Analyses of variance. A MANOVA was conducted on the episodic memory measures, with age and gender as independent variables. The analysis indicated significant effects of age [Wilks's $\lambda=.502, F(135,7531)=5.17$ ] and of gender [Wilks's $\lambda=.919, F(15,966)=5.67$ ]. The age $\times$ gender interaction was not significant. Since there was no interaction between age and gender in the present material, age was excluded from further analysis. For a detailed description of the influence of age on performance in these tasks, see Bäckman and Nilsson (1996), Erngrund, Mäntylä, and Nilsson (1996), Nilsson et al. (1997), and Nyberg, Bäckman, Erngrund, Olofsson, and Nilsson (1996).

In order to evaluate the effects of gender on recall of newly acquired facts, activities, $d^{\prime}$ for face recognition, given name recognition, and family name recognition, the information from the univariate $F$ tests in the MANOVA was used. There were main effects of gender for recall of newly acquired facts $[F(1,980)=34.40]$, activities $[F(1,980)=12.99]$, face recognition $[F(1,980)=$ $27.29]$, and given name recognition $[F(1,980)=6.72]$. The main effects of gender indicated that women performed at a significantly higher level than men in all these tasks. There was no effect of gender on family name recognition, however. 
Table 2

Means, Standard Errors, and Effect Sizes

for Men and Women Across Memory Tasks

\begin{tabular}{|c|c|c|c|c|c|}
\hline \multirow[b]{2}{*}{ Task } & \multicolumn{2}{|c|}{ Men } & \multicolumn{2}{|c|}{ Women } & \multirow{2}{*}{$\begin{array}{c}\begin{array}{c}\text { Effect } \\
\text { Size }\end{array} \\
\frac{d}{}\end{array}$} \\
\hline & $M$ & $S E$ & $M$ & $S E$ & \\
\hline \multicolumn{6}{|l|}{ Episodic Tasks } \\
\hline $\begin{array}{l}\text { Word Recall } \\
\text { Nondivided/nondivided } \\
\text { Nondivided/divided } \\
\text { Divided/nondivided } \\
\text { Divided/divided } \\
\text { Newly acquired facts } \\
\text { Memory for activities }\end{array}$ & $\begin{array}{l}4.99 \dagger \\
4.40 \dagger \\
3.62 \dagger \\
3.37 \dagger \\
5.05 \dagger \\
8.04 \dagger\end{array}$ & $\begin{array}{l}.072 \\
.068 \\
.063 \\
.063 \\
.136 \\
.154\end{array}$ & $\begin{array}{l}5.40 \\
4.74 \\
3.97 \\
3.68 \\
6.05 \\
8.67\end{array}$ & $\begin{array}{l}.073 \\
.073 \\
.066 \\
.063 \\
.134 \\
.142\end{array}$ & $\begin{array}{l}.25 \\
.22 \\
.24 \\
.21 \\
.33 \\
.19\end{array}$ \\
\hline $\begin{array}{l}\text { Free recall, cued recall, an } \\
\text { Free recall } \\
\text { Cued recall } \\
\text { Recognition, }\left(d^{\prime}\right)\end{array}$ & $\begin{array}{c}\text { on of SP7 } \\
9.99 \dagger \\
9.39 \dagger \\
3.22 \dagger\end{array}$ & $\begin{array}{l}.126 \\
.126 \\
.053\end{array}$ & $\begin{array}{r}10.76 \\
10.00 \\
3.59\end{array}$ & $\begin{array}{l}.112 \\
.119 \\
.044\end{array}$ & $\begin{array}{l}.29 \\
.22 \\
.34\end{array}$ \\
\hline $\begin{array}{l}\text { Free recall, cued recall, an } \\
\text { Free recall } \\
\text { Cued recall } \\
\text { Recognition, }\left(d^{\prime}\right)\end{array}$ & $\begin{array}{c}\text { on of sen } \\
6.21 \dagger \\
5.48 \dagger \\
2.17 \dagger\end{array}$ & $\begin{array}{l}\text { es } \\
.124 \\
.145 \\
.052\end{array}$ & $\begin{array}{l}6.81 \\
6.21 \\
2.38\end{array}$ & $\begin{array}{l}.126 \\
.144 \\
.049\end{array}$ & $\begin{array}{l}.21 \\
.22 \\
.19\end{array}$ \\
\hline $\begin{array}{l}\text { Face and name recognition } \\
\text { Face recognition, }\left(d^{\prime}\right) \\
\text { Given name } \\
\text { Family name }\end{array}$ & $\begin{array}{l}1.75 \dagger \\
5.63 \dagger \\
7.35\end{array}$ & $\begin{array}{l}.047 \\
.110 \\
.115\end{array}$ & $\begin{array}{l}2.04 \\
6.01 \\
7.49\end{array}$ & $\begin{array}{l}.047 \\
.113 \\
.116\end{array}$ & $\begin{array}{l}.27 \\
.15 \\
.05\end{array}$ \\
\hline \multicolumn{6}{|l|}{ Semantic Tasks } \\
\hline $\begin{array}{l}\text { General knowledge } \\
\text { Word knowledge }\end{array}$ & $\begin{array}{r}7.70 \\
20.98\end{array}$ & $\begin{array}{l}.077 \\
.260\end{array}$ & $\begin{array}{r}7.63 \\
21.26\end{array}$ & $\begin{array}{l}.082 \\
.239\end{array}$ & $\begin{array}{r}-.04 \\
.05\end{array}$ \\
\hline \multicolumn{6}{|l|}{ Primary Memory } \\
\hline \multicolumn{6}{|l|}{ Priming Task } \\
\hline $\begin{array}{l}\text { Target } \\
\text { Baseline } \\
\text { Priming }\end{array}$ & $\begin{array}{l}3.50 \\
2.28 \\
1.22\end{array}$ & $\begin{array}{l}.078 \\
.064 \\
.099\end{array}$ & $\begin{array}{l}3.7 \\
2.36 \\
1.34\end{array}$ & $\begin{array}{l}.076 \\
.055 \\
.091\end{array}$ & $\begin{array}{l}.12 \\
.06 \\
.06\end{array}$ \\
\hline
\end{tabular}

Note-Effect size, $d=\left(M_{\text {women }}-M_{\text {men }}\right) / S D_{\text {total }}$. A positive value of $d$ indicates that women performed at a higher level than men; a negative value indicates that men performed at a higher level than women. ${ }^{\dagger} p<.01$.

The effects of gender and division of attention on word recall were evaluated in a 2 (gender) $\times 2$ (encoding condition: focused, divided) $\times 2$ (retrieval condition: focused, divided) ANOVA, with repeated measures on the last two factors. There were main effects of gender $[F(1,998)=22.35]$, encoding condition $[F(1,998)=$ $1,035.02]$, and retrieval condition $[F(1,998)=168.49]$. These effects demonstrated that women performed at a higher level than did men, and that division of attention at both encoding and retrieval impaired performance. The encoding condition $\times$ retrieval condition interaction was significant $[F(1,998)=28.63]$, which reflected the fact that division of attention at retrieval had no effect if subjects' attention had been divided at encoding. None of the other interactions were reliable.

In order to analyze potential gender differences in free and cued recall of sentences and SPTs, we conducted a 2 (gender) $\times 2$ (task: sentences, SPTs) $\times 2$ (recall: free, cued) ANOVA, with task and recall as within-subjects factors. There were main effects of gender $[F(1,998)=$ $20.56]$, task $[F(1,998)=2,160.16]$, and recall $[F(1,998)=$
223.88]. The main effects indicated that women performed at a higher level than men and that SPTs were better recalled than sentences. In addition, subjects performed at a higher level in free recall than in cued recall. This result most likely reflects the fact that there was a longer retention interval between study and cued recall than between study and free recall. No interaction was reliable.

Hit and false alarm rates in recognition of sentences and SPTs were transformed into $d^{\prime}$ scores. A 2 (gender) $\times 2$ (task: sentences, SPTs) ANOVA on the $d^{\prime}$ data revealed main effects of gender $[F(1,998)=27.37]$ and task $[F(1,998)=746.82]$. These results indicated that women performed at a higher level than men and that SPTs were recognized better than sentences. The interaction was not reliable.

Regression analyses. Given that there were significant gender differences in verbal fluency, it was judged important to determine whether the gender differences in episodic memory would remain after statistical control of verbal fluency. Thus, to evaluate the relative influence of gender and verbal fluency on the episodic memory 
measures, we conducted a series of hierarchical regression analyses. As can be seen in Table 3, the 15 episodic memory measures were aggregated to form 10 dependent variables in the regression analyses. Two regression analyses were computed for each of the 10 episodic memory measures, one in which gender was entered first followed by Fluency 1 and Fluency 2 in one block, and one in which Fluency 1 and Fluency 2 were entered first in one block, followed by gender. As can be seen in Table 3, in all tasks except family name recognition, the effect of gender was reliable when entered first in the regression equations. More importantly, in all cases, the effect of gender remained when verbal fluency was statistically controlled.

\section{Semantic Memory, Primary Memory, and Priming}

Analyses of variance. A MANOVA was also conducted on the semantic memory, primary memory, and priming tasks. This MANOVA yielded a significant effect of age [Wilks's $\lambda=.793, F(45,4369)=5.17$ ]. Neither the effect of gender nor the age $\times$ gender interaction was significant. Since there was no interaction between age and gender, age was dropped from further analysis. As can be seen in Table 2, univariate $F$ tests in the MANOVA demonstrated that there were no effects of gender on gen- eral knowledge, word comprehension, primary memory, or priming.

Regression analyses. In order to evaluate the relative effect of gender and verbal fluency on general knowledge, word comprehension, primary memory, and priming, hierarchical regression analyses were conducted. The effect of gender was not reliable, irrespective of whether it was entered first or last in the equations. However, verbal fluency contributed reliably to the variance in the semantic and primary memory tasks (see Table 3 ).

\section{DISCUSSION}

Our main research question addressed whether there are gender differences in memory performance. The findings from the present study strongly suggest that such differences do exist. There were reliable differences between the population-based samples of men and women on all but one measure of episodic memory (recognition of family names). The reason for the lack of gender effect in recognition of family names remains unclear. However, although women outperformed men on the episodic memory tasks, there were no statistically significant differences between men and women on the measures of semantic memory, primary memory, or priming.

Table 3

Hierarchical Regression Analyses for All Memory Measures, With Gender and Verbal Fluency as Predictors

\begin{tabular}{|c|c|c|c|c|c|c|c|}
\hline \multicolumn{4}{|c|}{ Model 1} & \multicolumn{4}{|c|}{ Model 2} \\
\hline Measure & $\beta$ & Change $R^{2}$ & Cum. $R^{2}$ & Measure & $\beta$ & Change $R^{2}$ & Cum. $R^{2}$ \\
\hline \multicolumn{8}{|c|}{ Word Recall } \\
\hline Gender & -.15 & $.022 \dagger$ & .022 & Fluency 1 & .37 & $.279 \dagger$ & .279 \\
\hline Fluency 1 & .36 & $.269+$ & .291 & Fluency 2 & .22 & & \\
\hline Fluency 2 & .21 & & & Gender & -.11 & $.012 \dagger$ & .291 \\
\hline \multicolumn{8}{|c|}{ Newly Acquired Facts } \\
\hline Gender & -.16 & $.027 \dagger$ & .027 & Fluency 1 & .24 & $.130^{\dagger}$ & .13 \\
\hline Fluency 1 & .24 & $.119 \dagger$ & .146 & Fluency 2 & .15 & & \\
\hline Fluency 2 & .15 & & & Gender & -.14 & $.019 \dagger$ & .146 \\
\hline \multicolumn{8}{|c|}{ Memory for Activities } \\
\hline Gender & -.09 & $.009 \dagger$ & .009 & Fluency 1 & .30 & $.220 \dagger$ & .22 \\
\hline Fluency 1 & .30 & $.211 \dagger$ & .220 & Fluency 2 & .22 & & \\
\hline Fluency 2 & .22 & & & Gender & -.06 & $.003^{*}$ & .220 \\
\hline \multicolumn{8}{|c|}{ SPT Recall } \\
\hline Gender & -.14 & $.019 \dagger$ & .019 & Fluency 1 & .30 & $.208 \dagger$ & .208 \\
\hline Fluency 1 & .30 & $.200 t$ & .218 & Fluency 2 & .21 & & \\
\hline Fluency 2 & .20 & & & Gender & -.10 & $.011 \dagger$ & .218 \\
\hline \multicolumn{8}{|c|}{ Recognition of SPTs } \\
\hline Gender & -.17 & $.029 \dagger$ & .029 & Fluency 1 & .18 & $.074 \dagger$ & .074 \\
\hline Fluency 1 & .17 & $.068 t$ & .097 & Fluency 2 & .12 & & \\
\hline Fluency 2 & .12 & & & Gender & -.15 & $.220 \dagger$ & .097 \\
\hline \multicolumn{8}{|c|}{ Sentence Recall } \\
\hline Gender & -.11 & $.013 \dagger$ & .013 & Fluency 1 & .31 & $.200 \dagger$ & .20 \\
\hline Fluency 1 & .31 & $.192 \dagger$ & .205 & Fluency 2 & .18 & & \\
\hline Fluency 2 & .17 & & & Gender & -.08 & $.006 \dagger$ & .205 \\
\hline \multicolumn{8}{|c|}{ Recognition of Sentences } \\
\hline Gender & -.10 & $.009+$ & .009 & Fluency I & .22 & $.100 \dagger$ & .10 \\
\hline Fluency 1 & .22 & $.096 \dagger$ & .106 & Fluency 2 & .13 & & \\
\hline Fluency 2 & .13 & & & Gender & -.07 & $.006^{*}$ & .106 \\
\hline
\end{tabular}


Table 3 (Continued)

\begin{tabular}{|c|c|c|c|c|c|c|c|}
\hline \multicolumn{4}{|c|}{ Model 1} & \multicolumn{4}{|c|}{ Model 2} \\
\hline Measure & $\beta$ & Change $R^{2}$ & Cum. $R^{2}$ & Measure & $\beta$ & Change $R^{2}$ & Cum. $R^{2}$ \\
\hline \multicolumn{8}{|c|}{ Face Recognition } \\
\hline Gender & -.14 & $.019 \dagger$ & .019 & Fluency 1 & .22 & $.104 \dagger$ & .104 \\
\hline Fluency 1 & .22 & $.098 \dagger$ & .116 & Fluency 2 & .14 & & \\
\hline Fluency 2 & .13 & & & Gender & -.11 & $.013 \dagger$ & .116 \\
\hline \multicolumn{8}{|c|}{ Recognition of Given Names } \\
\hline Gender & -.07 & $.006^{*}$ & .006 & Fluency 1 & .08 & $.020 \dagger$ & .059 \\
\hline Fluency 1 & .08 & $.019 \dagger$ & .025 & Fluency 2 & .08 & & \\
\hline Fluency 2 & .08 & & & Gender & -.06 & $.004^{*}$ & .025 \\
\hline \multicolumn{8}{|c|}{ Recognition of Family Names } \\
\hline Gender & -.03 & .000 & .000 & Fluency 1 & .07 & $.039 \dagger$ & .039 \\
\hline Fluency 1 & .07 & $.039 \dagger$ & .039 & Fluency 2 & .15 & & \\
\hline Fluency 2 & .15 & & & Gender & -.01 & .000 & .039 \\
\hline \multicolumn{8}{|c|}{ General Knowledge } \\
\hline Gender & .02 & .00 & .00 & Fluency 1 & .21 & $.149 \dagger$ & .149 \\
\hline Fluency 1 & .21 & $.151 \dagger$ & .152 & Fluency 2 & .22 & & \\
\hline Fluency 2 & .22 & & & Gender & .05 & .003 & .152 \\
\hline \multicolumn{8}{|c|}{ Verbal Comprehension } \\
\hline Gender & -.02 & .00 & .00 & Fluency 1 & .34 & $.373 \dagger$ & .373 \\
\hline Fluency 1 & .34 & $.373 \dagger$ & .373 & Fluency 2 & .34 & & \\
\hline Fluency 2 & .34 & & & Gender & .02 & .000 & .373 \\
\hline \multicolumn{8}{|c|}{ Primary Memory } \\
\hline Gender & -.03 & .001 & .001 & Fluency 1 & .06 & $.018 \dagger$ & .018 \\
\hline Fluency 1 & .06 & $.017 \dagger$ & .018 & Fluency 2 & .09 & & \\
\hline Fluency 2 & .09 & & & Gender & -.02 & .001 & .018 \\
\hline \multicolumn{8}{|c|}{ Priming } \\
\hline Gender & -.03 & .001 & .001 & Fluency 1 & .03 & .005 & .005 \\
\hline Fluency 1 & .03 & .005 & .006 & Fluency 2 & .05 & & \\
\hline Fluency 2 & .05 & & & Gender & -.02 & .001 & .006 \\
\hline
\end{tabular}

Note - For word recall, the four encoding-retrieval conditions were significantly correlated, with $r$ s ranging from .43 to .53 , and were aggregated to form a composite word recall variable. For SPT recall, the correlation between free and cued recall of SPTs was significant $(r=.73)$, and the measures were aggregated to form one SPT recall variable. For sentence recall, the correlation between free and cued recall of sentences was significant $(r=.81)$, and the measures were aggregated to form one sentence recall variable. ${ }^{*} p<.04 . \quad \dagger p<.01$.

It has been found in a number of studies that women perform at a higher level than men on episodic memory tasks, such as recall of object locations (Eals \& Silverman, 1994; Hill et al., 1995), picture recall (Galea \& Kimura, 1993), word recall (Bolla-Wilson \& Bleecker, 1986; Geffen et al., 1990; Hill et al., 1995; Hultsch et al., 1991; Larrabee \& Crook, 1993; Rabbitt et al., 1995; Ruff et al., 1988; Schaie \& Willis, 1993; West et al., 1992; Zelinski et al., 1993), word recognition (Temple \& Cornish, 1993; Zelinski et al., 1993), story recall (Hultsch et al., 1991; Zelinski et al., 1993), face and name recall and recognition (Hill et al., 1995; Larrabee \& Crook, 1993; Wahlin et al., 1993; West et al., 1992), and odor recognition (Lehrner, 1993). Thus, the present study supports previous findings by confirming a higher level of performance for women in face recognition, given name recognition, and word recall and recognition. In addition, this study extends the list of episodic memory tasks influenced by gender, by demonstrating that women perform at a higher level than men on recall of SPTs, recall of words under conditions of focused and divided attention, recall of activities, and recall of newly acquired facts. Thus, it appears that the female superiority in episodic memory performance is rather consistent across different materials and encoding/retrieval conditions.

It is noteworthy that the magnitude of the female episodic memory advantage was similar across the tests of recall and recognition. The fact that the size of the genderrelated performance difference was similar in recognition and recall $\left(M_{d \text { Recog }}=.21 ; M_{d \text { Recall }}=.24\right)$ suggests that problems at encoding rather than retrieval may underlie the lower performance of the male subjects. If genderrelated retrieval problems had dominated, markedly reduced gender differences in recognition relative to recall would have been expected. Thus, the findings from the present study, along with previous results, indicate that there is now sufficient evidence to conclude that women perform at a higher level than men on episodic memory tasks in middle and old age.

By contrast, there were no differences between men and women on the semantic memory tasks, the primary memory task, or the priming task. Aside from the present study, only Hultsch et al. (1991) have investigated gender differences in semantic memory and priming. They demonstrated higher performance for men on a semantic world knowledge test and no gender differences on a 
priming task. Thus, in addition to priming being relatively immune to the effects of aging (Craik \& Jennings, 1992), this form of retrieval without conscious recollection does not seem to vary as a function of gender. The conflicting results regarding gender effects on semantic memory performance may reflect differences in the materials used.

Given that women perform at a higher level than men on episodic memory tasks, what are the possible reasons? It may be the case that the higher verbal ability of women brings about their better performance in episodic memory tasks. Yet although this explanation may appear reasonable, it is not fully convincing. In the present study, the primary memory task, the semantic memory tasks, and the priming task were also verbal in nature to the same extent as were most of the episodic memory tasks. If higher verbal ability is the source of women's better episodic memory performance, it would be reasonable to expect a female advantage on the nonepisodic verbal tasks as well. This was not the case. Moreover, the regression analyses indicated that, although verbal fluency contributed to the variance across all episodic memory tasks, statistical control of this variable did not eliminate the variance accounted for by gender in any episodic memory task. In addition, a verbal advantage cannot explain women's higher performance on face recognition, demonstrated in this study and other research (e.g., Hill et al., 1995; Shepherd, 1981; West et al., 1992). Thus, although a female advantage in verbal ability may contribute to gender differences in episodic memory performance, it does not fully explain these differences.

What other possible explanations for the obtained gender differences could there be? In some previous studies, the data pattern of gender differences has been interpreted as reflecting male/female interest, and/or differential familiarity for different kinds of material (McKelvie et al., 1993; West et al., 1992). This explanation does not account for several of the findings in the present study, however. For example, women performed at a higher level on recall and recognition of words, sentences, and SPTs, and on recall of recently acquired information. The materials in these tasks were carefully balanced, and consisted of several equivalent versions. It is therefore difficult to sustain the argument that the information to be remembered tapped female interests to a greater extent than it did male interests. In fact, except in the face recognition task, in which the faces were children's, there is no reason to suspect that the material in the episodic memory tasks unduly favored women. Other authors (Eals \& Silverman, 1994; Silverman \& Eals, 1992) have explained gender differences in recall of object locations as resulting from division of labor during evolutionary adaptation. Whereas men primarily were hunters and thus had opportunities to develop their spatial skills, women served as gatherers and were therefore shaped to develop their memory for object locations. Although this theory may account for gender differences in memory for locations, it cannot explain the general effects of gender on episodic memory performance obtained in the present study.
There is no consensus regarding the reasons for gender differences in visuospatial, numerical, and verbal abilities, although several hypotheses exist. The explanations for gender differences fall into two major categories: psychosocial and biological. Whereas the psychosocial explanations stress the importance of the environment and the expectations from the environment on the young child, the biological explanations refer to differences found between men and women in brain organization and morphology. A similar approach to explaining gender differences in episodic memory may be useful.

The subjects in the present study ranged from 35 years to 80 years of age. There was no overall age $\times$ gender interaction, indicating that the gender differences found in the episodic memory tasks were rather consistent across age groups. It has been reported that men, with increasing age, show a more pronounced brain volume decline, particularly in the left hemisphere, than do women (Gur et al., 1991). Gur et al. suggested that women may therefore be less susceptible to age-related cognitive decline than men. However, this hypothesis was not supported by the present data or by previously reported results (Larrabee \& Crook, 1993). By contrast, gender differences in episodic memory performance appear to be of similar magnitude from 35 to 80 years of age.

The differences between men and women, although highly significant, were small in terms of actual numbers. It could be argued that the differences are too small to merit interest. However, we believe that small differences cannot a priori be considered unimportant. The effect sizes obtained in the episodic memory tasks ranged from .09 to .34 , with a mean of .23 . These effect sizes should be compared with the effect sizes typically obtained on measures of visuospatial and verbal abilities. Linn and Petersen (1986) conducted a meta-analysis of gender differences in spatial abilities. Three broad categories of spatial ability were formed: spatial perception, mental rotation, and spatial visualization. The effect sizes for these categories varied substantially, being -.64 for spatial perception, -.26 for most tasks assessing mental rotation (a considerably larger effect size was found on the Vandenberg version of the Shepard-Metzler mental rotation task), and -.13 for spatial visualization, all in favor of men. Hyde and Linn (1988) conducted a similar meta-analysis of verbal ability and demonstrated that the weighted mean effect size was .11, favoring women. The analyses of effect sizes for different measures of verbal ability varied between -.16 and .33 , depending on type of task. Thus, it is apparent that the effect sizes for gender vary between visuospatial tasks and verbal tasks, but also within these task categories. The effect sizes for episodic memory found in the present study were around one quarter of a standard deviation unit, which is higher than those obtained for spatial visualization and verbal ability, and comparable with that obtained in mental rotation.

Why have gender differences in episodic memory not received legitimate attention in the scientific community? One reason may be that studies of human memory 
have for many years been concerned with basic research questions, typically with the use of experimental paradigms. Individual difference variables (e.g., gender) have played only a marginal role in this research. In addition, Maccoby and Jacklin's (1974) statement that there were no gender differences in learning and memory may not have fostered empirical inquiry into this topic. Even if tests for main effects of gender have been conducted in some studies, it is reasonable to assume that potential differences were not detected with the small sample sizes generally used in experimental memory research. However, in research on adult cognitive development, there has been an increasing number of longitudinal studies with large sample sizes and subjects ranging in age from young to old. The majority of previous studies reporting gender differences in episodic memory have been conducted within a developmental framework (e.g., Hill et al., 1995; Hultsch et al., 1991; Schaie \& Willis, 1993; Zelinski et al., 1993). It is probable that with the undertaking of more large-scale studies, gender differences in episodic memory performance will become more widely reported and discussed.

Based on data from a population-based sample of adults, the present study suggests that there is a reliable female advantage in episodic memory performance. Although we at present do not have a sufficient explanation for these results, future research should be done in order to evaluate the relative importance of social, psychological, and biological factors for the existence of this intriguing phenomenon.

\section{REFERENCES}

Bäckman, L., \& Nilsson, L.-G. (1996). Semantic memory functioning across the adult life span. European Psychologist, 1, 27-33.

Baddeley, A. D., Lewis, V., Eldridge, M., \& Thomson, N. (1984). Attention and retrieval from long-term memory. Journal of Experimental Psychology: General, 113, 518-540.

BOLLA-WILSON, K., \& BLEECKER, M. L. (1986). Influence of verbal intelligence, sex, age, and education on the Rey Auditory Verbal Learning Test. Developmental Neuropsychology, 2, 203-211.

COHEN, R. L. (1981). On the generality of some memory laws. Scandinavian Journal of Psychology, 22, 267-282.

Craik, F. I. M., \& Jennings, J. M. (1992). Human memory. In F. I. M. Craik \& T. A. Salthouse (Eds.), The handbook of aging and cognition (pp. 51-110). Hillsdale, NJ: Erlbaum.

DUREMAN, I. (1960). SRB: 1. Stockholm: Psykologiförlaget.

Eals, M., \& Silverman, I. (1994). The hunter-gatherer theory of spatial sex differences: Proximate factors mediating the female advantage in recall of object arrays. Ethology \& Sociobiology, 15, 95-105.

ERnGrund, K., MänTYlä, T., \& Nilsson, L.-G. (1996). Adult age differences in source recall: A population-based study. Journal of Gerontology: Psychological Sciences, 51 B, P335-P345.

Folstein, M. F., Folstein, S. E., \& McHugh, P. R. (1975). "MiniMental State": A practical method for grading the cognitive state of the patient for the clinician. Journal of Psychiatric Research, 12, 189-198.

Galea, L. A. M., \& Kimura, D. (1993). Sex differences in routelearning. Personality \& Individual Differences, 14, 53-65.

Geffen, G., Moar, K. J., O'Hanlon, A. P., Clark, C. R., \& Geffen, L. B. (1990). Performance measures of 16- to 86-year-old males and fermales on the Auditory Verbal Learning Test. Clinical Neuropsychologist, 4, 45-63.

Gur. R. C., Mozley, P. D., Resnick, S. M., Gottlieb, G. E., Kohn, M., Zimmerman, R., Herman, G., Atlas, S., Grossman, R., Berretta, D.,
ErwIN, R., \& GuR, R. E. (1991). Gender differences in age effect on brain atrophy measured by magnetic resonance imaging. Proceedings of the National Academy of Sciences, 88, 2845-2849.

HALPERN, D. F. (1992). Sex differences in cognitive abilities (2nd ed.) Hillsdale, NJ: Erlbaum.

HaRT, R. P., \& O'Shanick, G. J. (1993). Forgetting rates for verbal, pictorial, and figural stimuli. Journal of Clinical \& Experimental Neuropsychology, 15, 245-265.

Hill, R. D., Grut, M., Wahlin, A., Herlitz, A., Winblad, B., \& BäCKMAN, L. (1995). Predicting memory performance in optimally healthy very old adults. Journal of Mental Health \& Aging, 1, 55-65.

HULTER-ÅsBERG, K. (1984). The common language of Katz's index of ADL in six studies of aged and disabled patients. Scandinavian Journal of Cardiac Science, 2, 171-178.

Hultsch, D. F., Masson, M. E. J., \& Small, B. J. (1991). Adult age differences in direct and indirect tests of memory. Journal of Gerontology: Psychological Sciences, 46, 22-30.

HYDE, J. S., \& LiNN, M. C. (1988), Gender differences in verbal ability; A meta-analysis. Psychological Bulletin, 104, 53-69.

Kausler, D. H., \& HaKamI, M. K. (1983). Memory for activities: Adult age differences and intentionality. Developmental Psychology, $19,889-894$

LarrabeE, G. J., \& CRook, T. H. (1993). Do men show more rapid age-associated decline in simulated everyday verbal memory than do women? Psychology \& Aging, 8, 68-71.

LEHRNER, J. P. (1993). Gender differences in long-term odor recognition memory: Verbal versus sensory influences and the consistency of label use. Chemical Senses, 18, 17-26.

LinN, M. C., \& Petersen, A. C. (1986). A meta-analysis of gender differences in spatial ability: Implications for mathematics and science achievement. In J. S. Hyde \& M. C. Linn (Eds.), The psychology of gender: Advances through meta-analysis (pp. 67-101). Baltimore: Johns Hopkins University Press.

MACCOBY, E. E., \& JACKLIN, C. N. (1974). The psychology of sex differences. Stanford, CA: Stanford University Press.

McKelvie, S. J., Standing, L., St. Jean, D., \& LaW, J. (1993). Gender differences in recognition memory for faces and cars: Evidence for the interest hypothesis. Bulletin of the Psychonomic Society, 31, 447-448.

Nilsson, L.-G., Bäckman, L., Erngrund, K., Nyberg, L., AdolfsSON, R., Bucht, G., Karlsson, S., Widing, M., \& Winblad, B. (1997). The Betula prospective cohort study: Memory, health, and aging. Aging, Neuropsychology, \& Cognition, 4, 1-32.

NyberG, L., Bä́ckman, L., ERnGRUnd, K., Olofsson, U., \& Nilsson, L.-G. (1996). Age differences in episodic memory, semantic memory, and priming: Relationships to demographic, intellectual, and biological factors. Journal of Gerontology: Psychological Sciences, 51 B, P234-P240.

OLOFSSON, M., \& BÄCKMAN, L. (1996). Influences of intentionality at encoding and retrieval on memory in adulthood and old age. Aging/ Clinical \& Experimental Research, 8, 42-46.

Perris, C. (1984a). Life events and depression: Part 1. Effect of sex, age, and civil status. Journal of Affective Disorders, 7, 11-24.

Perris, C. (1984b). Life events and depression: Part 2. Results in diagnostic subgroups, and in relation to the recurrence of depression Journal of Affective Disorders, 7, 25-36.

PerRIS, C. (1984c). Life events and depression: Part 3. Relation to severity of the depression syndrome. Journal of Affective Disorders, 7, 37 44.

Rabitt, P., Donlan, C., Watson, P., Mcinnes, L., \& Bent, N. (1995). Unique and interactive effects of depression, age, socioeconomic advantage, and gender on cognitive performance of normal healthy older people. Psychology \& Aging, 10, 307-313.

Rosenthal, R. (1991). Meta-analytic procedures for social research (rev. ed.). Newbury Park, CA: Sage.

RufF, R. M., Light, R. H., \& Quayhagen, M. (1988). Selective reminding tests: A normative study of verbal learning in adults. Journal of Clinical \& Experimental Neuropsychology, 11, 539-550.

Schacter, D. L., Harbluk, J. L.. \& MacLachlan, D. R. (1984). Retrieval without recollection: An experimental analys is of source amnesia. Journal of Verbal Learning \& Verbal Behavior. 23, 593-611. Schacter, D. L., \& Tulving, E. (1994). What are the memory systems 
of 1994 ? In D. L. Schacter \& E. Tulving (Eds.), Memory systems 1994 (pp. 1-38). Cambridge, MA: MIT Press.

SChaIE, K. W., \& WILlis, S. L. (1993). Age difference patterns of psychometric intelligence in adulthood: Generalizability within and across ability domains. Psychology \& Aging, 8, 44-55.

SHEPHERD, J. (1981). Social factors in face recognition. In G. Davis, H. Ellis, \& J. Shepherd (Eds.), Perceiving and remembering faces (pp. 55-79). New York: Academic Press.

Silverman, I., \& Eals, M. (1992). Sex differences in spatial abilities: Evolutionary theory and data. In J. Barkow, L. Cosmides, \& J. Tooby (Eds.), The adapted mind: Evolutionary psychology and the generation of culture (pp. 487-503). New York: Oxford University Press. Statistiska CENTRALBYRÅn (1985). Betolkningens utbildningsnivå [Level of education for the population]. Örebro, Sweden: Author.

TEMPLE, C. M., \& CorNish, K. M. (1993). Recognition memory for words and faces in schoolchildren: A female advantage for words. British Journal of Developmental Psychology, 11, 421-426.

TULVING, E. (1983). Elements of episodic memory. Oxford: Oxford University Press.

Tulving, E. (1993). Human memory. In P. Andersen, O. Hvalby,
O. Paulsen, \& B. Hökfelt (Eds.), Memory concepts: Basic and clinical aspects (pp. 27-46). Amsterdam: Elsevier.

Tulving, E., \& Colotla, V. (1970). Free recall of trilingual lists. Cognitive Psychology, 1, 86-98.

Wahlin, Å., Bäckman, L., Mäntylä, T., Herlitz, A., Vittanen, M. $\&$ Winblad, B. (1993). Prior knowledge and face recognition in a community-based sample of healthy, very old adults. Journal of Gerontology: Psychological Sciences, 48, 54-61.

WECHSLER, D. (1981). Wechsler Adult Intelligence Scale-Revised Manual. New York: Psychological Corporation.

West, R. L., Crook, T. H., \& Barron, K. L. (1992). Everyday memory performance across the life span: Effects of age and noncognitive individual differences. Psychology \& Aging, 7, 72-82.

Zelinski, E. M., Gilewski, M. J., \& Schaie, K. W. (1993). Individual differences in cross-sectional and 3-year longitudinal memory performance across the adult life span. Psychology \& Aging, 8, 176-186.

(Manuscript received February 23, 1996; revision accepted for publication September 17, 1996.) 